\title{
TEMATOLOGÍA: CONSIDERACIONES SOBRE TEMA, MOTIVO Y MULTICULTURALIDAD
}

\section{THEMEOLOGY: CONSIDERATIONS ON THEME, MOTIF AND MULTICULTURALISM}

\section{S. Cristian Troisi}

Universidad de Málaga

\section{ABSTRACT}

Theme incorporates a term of a great force of evocation. Theme and motif can shape and filter the author's thinking (theme), move and move itself within the plot of a story (motif). The study of theme and motif, their communicative force, is essential to know about the connection between literary works from different cultures and fields. Cultural Studies that look on the ethno-anthropological social process and their connection to power, Gender Studies that point out on social construction, African-American Studies, New Historicism, all these cultural phenomena, and the social ones too, are characterized by a discursive centrality of a mainly thematic research; therefore, each trend has gone in this direction in a reasoned or in some cases a strategic and group way. The thematic research relevance and the different comparativism topic, such as their social links, constitute an undeniable hermeneutic nucleus that is dependent on thematologic inquiries.

Key words: Thematology, Thematic Criticism, Literary Theme, Literary Motif, Multiculturalism, Theory of literature 


\section{RESUMEN}

Tema enclaustra una palabra de gran fuerza evocativa. Tema y motivo son capaces de dar forma y filtrar el pensamiento del autor (tema) y de mover y de moverse dentro del enredo de un relato (motivo). El estudio del tema y de los motivos, su fuerza comunicativa, es imprescindible para conocer las conexiones entre obras literarias de diferentes culturas y ámbitos. Los Estudios Culturales, con su mirada hacia el proceso social etno-antropológico y su relación con el poder; los Estudios de Género, en sus observaciones sobre el construccionismo social, los Estudios Afroamericanos, el Neohistoricismo, todos estos fenómenos culturales, y también sociales, se ven caracterizados por la centralidad discursiva de una investigación primariamente temática; y así, cada corriente ha ido en esta dirección de manera razonada o en ciertos casos de manera estratégica y grupal. La relevancia de la investigación temática y del comparatismo en los diferentes discursos, y sus vínculos sociales, constituyen un núcleo hermenéutico innegable dependiente de las indagaciones tematológicas.

Palabras clave: Tematología, Crítica temática, Tema literario, Motivo literario, Multiculturalismo, Teoría de la literatura

Fecha de recepción: 29 de septiembre de 2020.

Fecha de aceptación: 24 de octubre de 2020.

Cómo citar: Troisi, S. Cristian (2020), «Tematología: consideraciones sobe tema, motivo y multiculturalidad», en Actio Nova: Revista de Teoría de la Literatura y Literatura Comparada, 4: 571 598.

DOI: https://doi.org/10.15366/actionova2020.4.024 


\section{INTRODUCCIÓN}

El tema y los temas, en general, en su acepción más amplia y con sus aspectos trascendentales, siempre han estado presentes en nuestra vida de manera fuerte y persistente. En ellos encontramos todos los aspectos que representan nuestra condición humana y que con mucha frecuencia se ven reflejados en las obras literarias o que proceden de ellas. La palabra tema enclaustra en sí lo imaginario, los mitos, los tipos psicológicos y sociales entre los cuales se puede identificar también el mismo escritor que a través del tipo humano se revela con su ideal estético y poético. Nosotros somos, indudablemente, lo que hemos vivido, nuestras experiencias y en alguna medida, lo que de lo vivido nos acordamos, lo que nos llega traducido, inducido por nuestra memoria, por eso los temas evocan nuestra experiencia que junto al imaginario llegan al receptor de la obra literaria y estética, llegan al lector.

\section{UNA CUESTIÓN HERMENÉUTICA: TEMA COMO «PREOCUPACIÓN O INTERÉS PARA LOS HOMBRES»}

Cada esfuerzo hermenéutico es por necesitad temático y tematológico. Los temas en su sentido puramente antropológico y ontológico han tenido siempre y siguen teniendo mucha importancia como objeto literario. Pichois y Rousseau definen los temas como algo que está profundamente ligado a nuestra existencia: «temas de preocupación o de interés general para los hombres» ${ }^{1}$. Chardin, refiriéndose a la noción del tema, enumera: «un rosario impresionante de términos» citados por R. Trousson y que están «empleados de manera más o menos intercambiable, en francés: mythe, theme, motif, idée, élément, type, figure, o en alemán Stoff, Fabel, Motiv, Figur, Bild, Idee, Element, ...» (Chardin, 1989: 132). En fin, no hay una verdadera coherencia en la definición de la noción de tema que toma las características o se acopla a la perspectiva del estudio, y en el campo de investigación se puede ver el tema como una macroestructura, como un enredo, como el fondo de un cuadro o simplemente como el objeto de la obra literaria.

\footnotetext{
${ }^{1}$ Fundamental a este propósito es el capítulo V, Estructuralismo literario, la parte dedicada a la Tematología en La Literatura Comparada.
} 
Temas, motivos, tipos, figuras, imágenes, son vistos como elementos y materia de estudio de la Tematología, que es una rama de la Literatura Comparada, aún poco definida en términos de metodología y terminología ${ }^{2}$.

Cuando hablamos de Tematología nos referimos, sin duda, a aquella dimensión abstracta de la literatura y a todas aquellas redes de conexiones que se despliegan y se concretan en el hecho literario en «el terreno de la obra de arte» (Guillén, 1985: 230). La materia prima literaria, «la materia elaborada de un texto» (Segre, 1985: 339), o sea, los materiales literarios de que está compuesta, así como sus variaciones intrínsecas y extrínsecas, sus renovaciones o revitalizaciones son: los temas y/o motivos según la escuela crítica a la que nos referimos. Estos actúan de forma selectiva, depurando, inspirando y alimentando el proceso de elaboración y de creación de las obras literarias. (Pimental, 1993: 215).

\subsection{RaÍCES HISTÓRICAS DE LA TEMATOLOGÍA}

La historia de la Tematología empieza cuando también la Literatura Comparada adquiere su importancia de disciplina académica. Dentro del análisis contrastivo que es propio de la Literatura Comparada, en esa perspectiva de la representación literaria encontramos todos los elementos que determinan e identifican la Tematología: los temas, los motivos, los personajes históricos y míticos, y, a la vez, cada forma de estereotipos desarrolla un papel de gran importancia dentro de este ámbito de estudios literarios. Nos ayuda a comprenderlo Naupert:

A este respecto hay que decir que la simbiosis entre ambos campos -tematología y literatura comparada- no ha sido nunca perfecta, muchas veces fue conflictiva y hasta dada por imposible. Pero, a pesar de todo, nunca hubo un comparatismo completamente ajeno a las propuestas y métodos de la Tematología, como tampoco hubo jamás un estudio sin una mínima inquietud comparatista (Naupert, 2001: 9).

Tenemos que añadir el ansia de encontrar una raíz común indoeuropea de todos los mitos, el interés por su procedencia y también por su recorrido histórico; y así los materiales mitológicos y literarios más heterogéneos formaban parte de la utopía que comienza sus

\footnotetext{
${ }^{2}$ Señala Ceserani: «Nonostante tutto questo lavorio, a me pare che ci sia ancor oggi, rispetto alla critica tematica, un deficit di proposte metodologiche omogenee e dettagliate, che esistano alcune grosse difficoltà teoriche non del tutto risolte, a cominciare dalla definizione stessa di tema (per non dire dell'intricata, disperante questione della differenza tra tema e motivo), e che ci sia purtroppo negli studi in questo settore una notevole confusione terminologica, con proposte disparate che vanno da tema a topos ad archetipo a immagine a simbolo a mito»(Ceserani, 2008: 27).
} 
primeros pasos ya en época prerromántica y que se concreta con el romanticismo europeo, en el inicio de la poética moderna. Las instancias y la búsqueda del mito común en la poesía popular y el mito de la misma poesía seguramente germinan antes con el prerromanticismo inglés de Thomas Percy, y siguen, después, con nueva fuerza e impulso con los alemanes hermanos Grimm y Johann Gottfried Herder. A este propósito, es importante señalar cómo el antropólogo italiano Giuseppe Cocchiara en el prefacio de la edición italiana de la editorial turinesa Einaudi de los Cuentos de los hermanos Grimm nos detalla lo siguiente:

È noto infatti che furono le Reliquies of Ancient English Poetry, edite dal Percy nel 1765, a porre, decisamente in Europa, l'attenzione non solo sulle ballate inglesi e scozzesi, ma anche sulla poesia popolare in genere, la quale, fin d'allora, veniva opposta alla poesia classicheggiante del tempo. Ed è noto altresì che quando lo Herder iniziò la raccolta dei Volkslieder, egli voleva dare alla Germania lo stesso libro che all'Inghilterra aveva dato il Percy. Con una differenza: che nello Herder il concetto di poesia si convertiva in quello di poesia popolare, la quale veniva considerata come un patrimonio nazionale che appartiene al mondo e ai popoli (Grimm, 2015: vii-viii).

La fabulación, el arte de contar tiene una relación específica con las antiguas tradiciones culturales míticas y legendarias, encajables en gran medida en el vasto dominio de la tradición oral. Los folkloristas en este campo han hecho una aportación relevante. Y de esta forma, los motivos, que cada vez se han insertado en los cuentos, siguen teniendo un valor extraliterario antes de que hayan sido enclaustrados en el canon de la literatura popular que, por sus características, tiende a repetirlos con una cierta recursividad. Este valor extraliterario aún se mantiene incluso cuando estos motivos vuelven a ser parte de una literatura más culta o de alto nivel.

Sin embargo, esta posición ante el folklore, esta importante rama del saber que tiene como materia de estudio transcendental la civilización de un pueblo en la totalidad de sus aspectos, y que, además se entiende representado en la literatura oral, está matizado por R. Wellek y A. Warren en el capítulo correspondiente y muy esclarecedor de «Literatura general. comparada y nacional», de su Teoría literaria, que tendremos presente y donde afirman que el estudio de la literatura oral es parte integrante de la investigación literaria, cuando muy a menudo no se puede separar de la obra escrita; es decir, hubo y sigue habiendo una correspondencia constante entre la literatura oral y la literatura escrita. Completan el concepto afirmando que: el estudio de la literatura oral ha de formar parte del bagaje de competencias de todo el estudioso de la literatura que quiera comprender los procesos de desarrollo literario, las bases y el origen de nuestros géneros y formas literarios (Wellek y 
Warren, 1974: 58). Algunas líneas después lo resumen de manera lacónica: «existe entre la literatura oral y la escrita una continuidad que no se ha interrumpido nunca» (Wellek y Warren, 1974: 59).

Concepto que, de otra forma, se ve reflejado en Pichois y Rousseau. Los dos autores analizan el papel de la literatura frente al folklore y dentro del marco del estructuralismo literario donde sitúan los estudios tematológicos, declinando lo imaginario que toma como punto de partida «lo maravilloso folklórico»:

Viejo como el mundo, lo maravilloso folklórico, transmitido por la tradición oral, inspira cierta desconfianza, por lo movedizas que son las fronteras entre lingüística, la antropología, la mitología y la religión. La misma noción de cultura folklórica, la paradoja de una literatura no escrita (¿qué existencia pueden tener textos que no estén congelados, como diría Rebelais?), esa es la cuestión que Europa se plantea desde fines del siglo XVIII.

Dentro de esta línea, la literatura comparada estudiará el paso de una Edad Media popular al culto Renacimiento, evolución mucho más tardía que la del Medioevo histórico, ya que acaba de producirse en ciertos países apartados (Pichois y Rousseau, 1967: 167).

Como hemos dicho antes, una de las complicaciones para tener una nítida delimitación del marco teórico de la Tematología, es la terminología indeterminada que se utiliza en esta rama de los estudios comparativos. Claramente esta situación se amplifica si consideramos el panorama multilingüe que es propio de los estudios del comparatismo literario. Temas, materia y motivos no han sido legados solamente desde lo que constituye el ambiente cultural europeo, se encuentran así mismo en más amplios contextos culturales que incluyen el mundo árabe y la cultura oriental: «De allí resulta consecuentemente la tendencia a la superación de límites, a la desatención de barreras del lenguaje y de los limites específicos de los métodos. A causa de esta pretensión surgida histórico-culturalmente tropieza entonces muy pronto con los límites de su capacidad y se ve obligado a la colaboración interdisciplinaria» (Beller, 1984: 110). La multitud de términos se desparraman en el variopinto cuadro de traducciones y adaptaciones de los diferentes aparatos terminológicos nacionales, por lo cual, se ha determinado una carencia de precisión que afecta al necesario rigor científico, que ablanda, aunque no lo niegue por completo. En comparación con ello, encontramos en las ciencias naturales un enfoque supranacional como la Tematología, pero se diferencia con esta por poseer un metalenguaje que es compartido por las varias comunidades científicas internacionales.

La Tematología empieza a dar sus primeros pasos en la segunda mitad del siglo XIX. Claudio Guillén (1985: 248) en su Entre lo uno y lo diverso nos señala como precursores de esta 
rama del comparatismo, entonces, a Max Koch con su Zur Ein führung, a la Zeitschrift für Vergleichende Literaturwissenschaft ${ }^{3}$, I de 1887, y a Arturo Graf en La leggenda del Paradiso Terreste de 1878.

Aunque sus orígenes se encuentran así lejanos en el tiempo, la Tematología, el análisis de los temas literarios no siempre ha contado con buena fama. Excesivamente exaltada por estudios positivistas, ha sido demasiado propensa a la simple catalogación mecánica o solo pendiente de proseguir caminos evolutivos; exageradamente obstaculizado, lo tematológico ha sido maltratado, e incluso removido por las escuelas posteriores: el Idealismo ${ }^{4}$ polarizado, cerrado sobre los textos; por el Formalismo, que, de manera un tanto unilateral, se ha ocupado de la pura forma; por el Estructuralismo, centrado en la estructura y en su consideración exclusiva o preeminente del aspecto formal de la obra sobre lo estético; o por la teoría deconstruccionista, convencida de la deriva de la idea o del mismo concepto en la obra de arte. A este propósito escribe Remo Ceserani que: «Roman Jakobson la chiamava con disprezzo la «critica del cavallo», alludendo alle noiose e spesso inutili ricerche di raccolta di materiali e classificazione di dati grezzi del lavoro letterario cari alla critica positivistica (il tema del cavallo nella poesia cavalleresca, cavalli e cavallerizzi nel romanzo vittoriano, ecc.)» (Ceserani, 2008: 25).

Durante mucho tiempo, en los estudios tematológicos, predominó el término Stoffgeschichte ${ }^{5}$ para indicar lo que ahora conocemos como Tematología. Stoffgeschichte es un término alemán que fue utilizado bastante como préstamo extranjero en el ámbito de esa diciplina, seguramente debido al hecho de que existe una importante tradición alemana de estudios en este campo. El significado de Stoffgeschichte tal vez puede resultar controvertido.

El término Stoff cuyo origen etimológico proviene del italiano stoffo/stoffa, o sea tejido, llega al alemán a través del neerlandés en el siglo XVII ya que los Países Bajos tenían una industria textil de mayor envergadura que la alemana (Naupert, 2001: 78). Stoff, como decíamos antes, conlleva en sí una polisemia que, al traducirlo al español, tendríamos que emplear el término tejido o tela; pero, entrando más en los significados generales o en los

\footnotetext{
${ }^{3}$ Primera revista de literatura comparada alemana que se centraba de forma exclusiva en la Tematología comparatista (1887-1910).

4Sobre ello, B. Croce: «Devo fare una confessione, non solo mia, ma anche confermata confidenzialmente da accademici più specializzati in questa area di me: non c'è nessun studio più arido che una ricerca di questo tipo.» (Croce, 1903: 78).

${ }^{5}$ Para comprender mejor este término véase el artículo de Manfred Beller (1970) traducido al español en Naupet (2003).
} 
figurados ese término se podría traducir como: materia, argumento, sustancia, material, asunto, objeto del discurso y por fin, tema (Naupert, 2001: 78).

Geschichte se puede traducir por historia o narración o discurso. Naupert precisa: «Acotando el polivalente término Stoff, se ha de subrayar en primer lugar que no se trata de la infinita materia poetizable que el autor puede encontrar en el mundo natural y en la historia social (el mundo humano). Así que no se puede hablar de Stoff en el sentido de Rohstoff (materia prima o bruta) extraliterario.» (Naupert, 2001: 78). Claramente esta materia bruta no forma parte de lo ponderable, sino que representa algo metaliterario que resulta poco tangible y que no puede ser materia de análisis literario comparativo. Como, por otra parte, no podemos hablar de materia prima en sensu stricto cuando hablamos de tema (Frenzel, 1966: 24), ya que eso presupone un objeto que no tiene forma y que todavía tiene que ser forjado y plasmado, tampoco podemos hablar de un tema en grado cero, es decir que no tenga ningún tipo de organización formal, aunque sea elemental o básica.

Según Frenzel, la materia poética es un objeto que de alguna manera ha sido seleccionado de las materias primas ofrecidas por el mundo natural y social, y se ha vuelto el objeto de la fábula y de la poesía siendo esto el sustrato para la formulación oral y literaria.

Claudio Guillén nos describe un episodio epistolar entre Schiller y Goethe en el cual ya se va delineando este pensamiento, y escribe: «Schiller explicaba, en carta a Goethe, que el quehacer poético arranca de oscura, casi inconsciente idea, Totalidee, que necesita un Objekt luego para realizarse.» (Guillén, 1985: 249).

¿Cómo puede circunscribirse o delimitarse esta inmensa materia poética? ¿Cómo identificar el objeto?

Claudio Guillén se deja guiar por Dámaso Alonso hacia el camino que va desde la forma al tema o viceversa, y constata que es el crítico quien «elige, extrae, cita», es decir, que las formas o los temas se constituyen, y, también a través del mismo lector que participa en el montaje y la construcción del sentido de estos elementos parciales; añade, además que «tratándose de tematología, esta intervención será tanto más importante cuanto más amplio o rico sea el panorama histórico que el comparatista procure otear, o más relevantes los fenómenos de intertextualidad que identifiquen el tema mediante la memoria de figuraciones anteriores.» (Guillén, 1985: 230).

Manfred Beller (1984) autor de «Tematología», artículo publicado en Alemania en 1981, es consciente de la complejidad que abarca el término tema, y, junto a ello, del laberinto teórico que es ínsito en la diciplina que lo estudia. Su análisis tiene pujanza crítica y su 
detallada mirada va hacia lo particular sin olvidarse de lo general, o más específicamente, citando a Claudio Guillen «entre lo uno y lo diverso». Como es evidente en su enfoque teórico, sus miras son amplias, llevándonos un paso más allá de la aproximación histórica de las escuelas germanistas de materias y motivos y de la escuela romanista de temas y también motivos. Refiriéndose al estudio tematológico de las categorías tanto sustantivas como formales, dice que ambas se han de tener en cuenta, no obstante las disonancias, las conceptualizaciones políglotas y los nuevos métodos en los diferentes campos filológicos de las varias nacionalidades:

[...]existe un innegable acuerdo fundamental sobre la influencia o efecto recíproco de las ideas, materias y motivos generales, así como las imágenes, topoi, y estructuras específicas, al menos entre las obras de las lenguas clásicas y modernas europeas y sus literaturas. Puesto que en el comercio interliterario limítrofe han crecido duraderas y ramificadas líneas de tradición, la perspectiva histórica determina ya la antigua historia germanista de materias y motivos, lo mismo de la escuela romanista dedicada a la historia de los temas y motivos. Una investigación de temas más recientes, más general e internacional incluye también la investigación de los símbolos y de los elementos formales de la tópica, la emblemática, la alegórica y la metafórica. En tiempos recientes, la relación entre temática y situación histórico-política despierta creciente interés (Beller, 1984: 103).

Después de una larga tradición positivista e historicista de los estudios tematológicos, donde estos encauzaban su investigación con un perfil diacrónico, en los años 30, en Alemania se impuso la Geistesgeschichte, o sea, la historia del espíritu que suplantaba a la Stoffeschichte de matriz positivista. Se pasó entonces de un estudio de tipo longitudinal historicista y diacrónico a un estudio más transversal. De esa forma, el cambio que se produjo fue metodológico y epistemológico, aunque entre las dos disciplinas no se dio un hiato si bien la Geistesgeschichte fue una evolución de la tradición decimonónica de la Stoffgeschichte. Gerhard Kaiser nos da su visión evolutiva, y escribe que la crítica del positivismo por parte de las humanidades y, posteriormente, por parte del formalismo ${ }^{6}$, llevaron a un énfasis discrepante respecto a los puntos esenciales de la investigación teórico-literaria, pero, no a la ruptura con toda la tradición histórica del estudio de temas y argumentos. Especialmente, en el comparatismo se mantuvieron aún por un tiempo las orientaciones positivistas. Continúa

\footnotetext{
${ }^{6}$ A este propósito García Berrio subraya como: «La gran novedad, como ya hemos indicado, del formalismo ruso respecto a la doctrina temática tradicional radica, sin duda, en la desvinculación de los elementos temáticos de la esfera de lo personajes. La transformación es tal que los mismos personajes pierden toda consistencia sustancial a los ojos de los formalistas para adquirir relieve exclusivamente funcional, como soporte de motivosfunciones. El llamado carácter personaje, las «mores» de la Poética clásica, no es otra cosa que un sistema de motivos» (García Berrio, 1973: 216).
} 
Kaiser afirmando que tampoco el interés de la Historia del Espíritu de la Geistesgeschichte por fenómenos como el amor o la muerte, se apartaba demasiado de la historia tradicional de los motivos y argumentos, y de esa manera, siguiendo la estela que la escuela de Waburg había trazado, la investigación sobre la tradiciones fue renovada, a un alto nivel casi siempre y de forma duradera, con lo que se puede hablar de una continuidad ininterrumpida de los análisis sobre la historia de los motivos y argumentos más allá de las dos guerras mundiales (Kaiser, 1980: 80).

Paul Van Tieghem, igualmente en los años 30, fue el primero en proponer el uso del término «thématologie» en lugar del término alemán Stoffgeschichte. Cuarenta años más tarde Manfred Beller en su «Von der Stoffgeschiche zur Thematologie» argumentará de forma sobresaliente, sin ninguna digresión, la razón por la cual el término de Stoffgeschichte ha sido conceptualmente superado.

Manfred Beller, dentro de un marco comparatista, impulsando una intensificación filológica, nos define cuáles son los dos principales problemas de la historia temática tradicional: el primero es la «desintegración» impuesta por la modernidad a las estructuras clásicas de fábula; el segundo es el aprovechamiento que de forma sistémica sostiene el análisis temático de la exégesis literaria. Por eso el término tema se acerca más profundamente a la dimensión histórica del campo de investigación de la poesía moderna que el concepto Stoff de concepción sin embargo más moderna pero también más reducido por su estrecha relación con el concepto materia. Y podíamos añadir que este concepto seguramente no cambiará si lo miramos desde una perspectiva teórico-literaria.

Continúa Beller partiendo de la base indogermánica «dhè» que significa «poner», «colocar», y siguiendo con el griego, y su término tema que significa «lo puesto, la disposición, también la creación, el orden y la base». Dándose, además, el hecho de que, históricamente, el término Stoff incorpora en sí mismo la historia de argumentos/temas al que le falta para completarse la historia de las formas, lo que por otro lado completa el significado de tema, como lo definía Levin en lo «polisémico», o Trousson en lo «polivalente». Concluye Beller: «Tematología abarca el objeto tradicional de la Stoffgeschiste, y a la vez lo supera gracias a la inclusión extensiva de todos los fenómenos temáticos y también gracias a la intensificación de los métodos filológicos» (Beller, 2003: 153).

La investigación de los temas en la literatura, en gran medida, se puede también resumir como un estudio de figuras, imágenes y representaciones de la real. Un estudio, así, se desarrolla de dos maneras básicas que están claramente interconectadas: el tratamiento del 
tema y de los temas como componentes de una única obra literaria, y el análisis de la recursividad del tema y su dinámica en la tradición. Como concepto, tema, se define, en este sentido, en los diversos campos de estudio de manera diferente; así, por ejemplo: figura, grupo de figuras, el entretejido de figuras, o por su dinámica combinatoria tanto como secuencial. Junto a ello, el otro aspecto importante en el estudio del tema, y que no debe subestimarse, es todo aquello que concierne a la Tematología comparada.

\section{HACIA UNA DEFINICIÓN DE TEMA Y MOTIVO}

En este punto importa preguntarse: ¿Qué es tema y qué es motivo? ¿Cuáles son las diferencias entre los dos elementos? ¿Qué características tienen?

En lo siguiente no pretendemos dar una definición unívoca de tema y motivo, más bien haremos una recopilación de las varias definiciones, destacando la más sugestivas a nosotros juicio. Los dos términos, tema y motivo, están en una estrecha relación entre sí. En general la crítica ha definido el concepto de «tema» teniendo siempre en cuenta ese vínculo entre estos dos términos.

\subsection{HACIA UNA DEFINICIÓN DE TEMA}

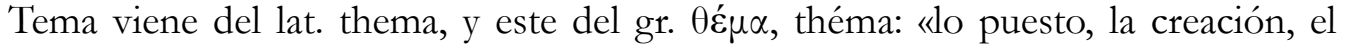
orden, la base» es cemento con el que se plasma una obra literaria. El tema «es la materia elaborable (o elaborada) en el discurso [...] Tema es, por lo tanto, según las definiciones, la materia elaborada en texto (es muy significativo el hecho de que en alemán tema se corresponde a Soff «materia») o bien asunto cuyo desarrollo es el texto, o bien la idea inspiradora» (Segre, 1985: 337).

B. Tomachevskij afirmó que el texto narrativo es una combinación de oraciones que están unidas entre sí por medio del tema, que representa la idea común. El tema reúne en sí los motivos que son unidades menores que se organizan en base a su correlación temporal, 
que puede ser casual o no casual. Las fábulas ${ }^{7}$ son los marcos temporales mientras que el enredo está constituido por todos estos elementos:

Boris Tomaševskij estudia los elementos temáticos mínimos del texto narrativo, los motivos, como unidades estructurales, quedando identificados dichos elementos, al igual que en la teoría de Propp, como entidades generales o abstractas del texto narrativo, en cuyo estrato más profundo forman una estructura que reproduce la organización de la realidad que constituye el referente de aquél. Dicho estrato, denominado fábula, está constituido por el contenido de la obra, con independencia de la disposición a la que es sometido para su presentación, y caracterizado, por consiguiente, por su ordenación lógica y cronológica (Albaladejo, 1998: 62).

Tomachevski nos da una definición de tema no demasiado precisa: «El tema (aquello de lo cual se habla) está constituido por la unidad de significados de los diversos elementos de la obra. Puede hablarse del tema de toda la obra, o de temas de las distintas partes» (Tomachevski, 1982: 179).

A su vez, Trousson entiende la dicotomía tema-motivo como una sinécdoque, como la dialéctica entre lo particular y lo general, que conecta el tema al motivo. Asimismo, divide los temas en dos categorías: los «temas de héroes»y «los temas de situaciones». El tema del héroe estaría representado por Prometeo que personifica el genio, la libertad y el progreso. Al tiempo que un tema de situaciones, por ejemplo, viene representado por Edipo porque necesita estar inmerso en la situación para tomar forma, para manifestarse como tema. La perspectiva de estudio de Trousson es diacrónica, analiza principalmente el carácter dinámico y evolutivo que para el teórico es la esencia misma del tema.

Según Claudio Guillén, tema es lo que asiste al escritor a encarnarse en el exceso y la riqueza de lo vivido, y marca una frontera entre la poesía y la experiencia; el tema es sinónimo de «tema estructurador». El tema implica una forma (y no pueden ir separados), y es lo que el escritor modela, transforma, o modula lo que trastorna. No es lo que se dice, sino aquello con lo que se dice, sean cuales sean sus características. El comparatista cita como ejemplo, entre otros, la Andromaque de Racine (Guillén, 1985: 252).

\footnotetext{
${ }^{7}$ Como acercamiento al concepto de fábula, véase la siguiente cita de Tomás Albaladejo Mayordomo: «La fábula, como ha quedado descrito en el capítulo anterior, por estar en su armazón de mundos constituida por los mundos de los distintos personajes que la componen y, consiguientemente, por los submundos que componen cada submundo, es una estructura multilineal, en la cual el desarrollo narrativo tiene lugar a lo largo de dicha pluralidad de líneas. En esta disposición la fábula reproduce el carácter multilineal de la estructura de conjunto referencial, denotación textual formada por los mundos, con sus submundos, de los personajes que el texto narrativo expresa en la medida en que son intensionalizados en el mismo, y esta organización, tanto de la estructura de conjunto referencial como de la estructura macrosintáctica, implica la posibilidad de desarrollo narrativo simultáneo de diferentes líneas, es decir, de diferentes mundos de la armazón» (Albaladejo, 1998: 192).
} 
Manfred Beller, retomando a Lausberg (1963: 29), señala que el tema designa la tarea propuesta al orador por la materia o el objeto del proceso. La elaboración del tema está ligada a las fases de la invención, de la ordenación y de la exposición verbal y de la elocución o exposición verbal. Añade que «El concepto de tema va, según la ubicación estético-literaria, desde los presupuestos extra o pre-literarios, pasando por la comprobación del contenido, hasta la interpretación de las obras poéticas» (Beller, 1984: 105). Reafirma, al mismo tiempo, que, como ya hemos visto, el término tema engloba en sí mismo aquello proveniente de Stoff. Nos da, también, algunas pautas parciales, pero no define claramente que es tema.

Trocchi aporta la siguiente perspectiva: el tema se refiere solo a los «temas de preocupación o de interés general para los hombres», retomando el concepto ya expresado por Brunel, Pichois y Rousseau, y añadiéndole la sustancial característica de transmisibilidad y temporalidad: «que se depositan en horizonte histórico-literario trasmitiéndose. En perspectivas de larga, mediana o corta duración» (Trocchi, 1999: 157).

Los rasgos temáticos son dinámicos, cambiantes y, añadimos nosotros, hipertextuales ya que poseen la capacidad de formar unas redes de conexiones entre textos de épocas y géneros diferentes, y asimismo de vínculos metaliterarios. Pueden ser de carácter general, y recorrer diferentes épocas, o temas más concretos y costumbrista que caractericen una época en particular, y que no podrían pertenecer a otra y ni siquiera ser entendidos; o pueden pertenecer a lo íntimo del autor, lo que se encuentra en el lugar más recóndito del sentimiento, es decir, aquello que es intrínseco al espíritu.

\subsection{HACIA UNA DEFINICIÓN DE MOTIVO}

Los motivos son unidades mínimas ${ }^{8}$, que «jerárquicamente» están por debajo de los temas; sin embargo, a veces no son de menor importancia. Estos componentes mínimos, reuniéndose entre ellos, constituyen el núcleo del tema, «ambos tecnicismos son genética y estructuralmente diferenciados, pero se confunden con frecuencia $[\ldots]$ "el motivo" representa una unidad intensa necesariamente integrada en la extensión narrativa del "tema"» (García Berrio y Hernández, 2008: 378). Son unidades temáticas pequeñas e indivisibles. Como la palabra motivo proviene del lat. tardío motivus, «relativo al movimiento» (Diccionario de la Real Academia Española, 2020), todo apunta al hecho de que la dinamicidad de estos

${ }^{8}$ La noción de motivo como unidad mínima de significado la elabora por primera vez el crítico B. Tomachevski en 1925. 
elementos es grande, sin embargo, son reducidos en número, mientras que los temas se presentan ilimitados.

La palabra motivo es un préstamo de la música. Estrechamente ligado al tema, en términos musicales, de donde procede. La repetitividad en una pieza o una sección de esta constituye su marco distintivo. Segre afirma que el concepto ya puede detectarse en el siglo XVII, en un texto italiano, con la acepción mencionada: «frase musical que se reproduce con modificaciones en un fragmento y le da su carácter (Wartburg, 1967: 162, en Segre, 1985: 347)». Goethe es quien introduce el término en la literatura (Kalinowska, 1972). Así mismo, se empezó a intentar definir qué eran los motivos con relación al campo de los estudios folklóricos, situándonos a finales del siglo XIX; y algo más tarde, pero en la misma época, los formalistas rusos se interesaron por los motivos y por su importancia analítica y cultural (Orea, 2018: 169).

Acerca de esta indagación sobre los motivos, interesa completar el concepto señalando que: «Los motivos libres acumulan las llamadas tópicas literarias, de modo que las escuelas literarias tienen predilección por algunos motivos, por ejemplo, el cabello rubio y ojos claros en la tópica renacentista» (Gil-Albarellos, 2003: 213).

Claudio Guillén, sobre los motivos, escribe que existen elementos temáticos menores como las imágenes y los rasgos. Ninguno de estos dos motivos asume un poder explicativo, no tienen una verdadera significación sino por ellos mismos, como el blanco del cetáceo Moby Dick, al vehicular una unidad significativa (Guillen, 1985: 252-253).

Doležel en su famoso artículo From Motifeme to Motif predica el motivema como término temático interpretativo del acto de un actante. El sistema motivema se define por dos series de expresiones que interpretan el acto, así como el actante que se reúnen en el vocabulario del motivema, a eso tenemos que añadir una función de motivema que asigna las expresiones particulares del acto y las expresiones particulares del actante; concretamente: «The system of motifemes is then a set of propositions defined on the motifeme vocabulary by the motifeme function» (Doležel, 1972: 59).

El motivo es una proposición que una acción a un personaje. Ningún motivo de función se puede definir; eso significa que un personaje puede realizar cualquier acción y, por el contrario, se puede asignar una acción a cualquier personaje (Doležel, 1972: 60). El motivema es entonces, el acto de un actante, lo que lo distingue del motivo, como acto de un actor. Motivos diversos pueden corresponder a un mismo motivema. 
Frenzel, en 1966 en su Stoff-und Motivgeschichte, esboza una definición de motivo afirmando que son unidades «a la vez más grandes y pequeñas que la fábula especifica de la acción». (citado por Naupert, 2001: 101). Esta conceptualización completa lo que había afirmado en su Stoff-, Motiv-und Symbolforschung de 1963:

La palabra motivo designa una pequeña unidad temática que no llega a comprender la totalidad de un plot o de un relato, ya que representa un elemento de contenido de situación. En poesías de contenido no muy complejo puede ser representado de forma condensada por el motivo nuclear pero habitualmente el contenido está formado en lo géneros literarios pragmáticos por más de un motivo. Para la lírica, que no tiene un verdadero y proprio argumento y por lo tanto no tiene tema...la única sustancia temática está formada por unos varios motivos (citado por Segre, 1985: 349).

Así pues, analizando estos enunciados resulta que los motivos son más fecundos y móviles que los argumentos que poseen un extendido sistema de relaciones.

Greimas observa en los motivos características independientes del tema: «El motivo aparece como una unidad de tipo figurativo que posee, pues, un sentido independiente de su significación funcional con relación al conjunto del relato en el que se sitúa» (Greimas y Courtés, 1990: 269).

Describiendo como el término «tematología» sea un conjunto indisociable de forma -contenido, materia- manera, y examinando la labor de Frenzel, en Compendio de Literatura Comparada, Chardin nos expone cómo, en su opinión, la teórica alemana denomina los dos conceptos de tema y motivo de la siguiente manera: «[...]"tema” (los materiales primarios de base) con lo que ella denomina los motivos (que tendrían a su vez una función estructurante de entrada): por ejemplo, el Grial sería según ella un tema que tiene como motivo la búsqueda» (Chevrel, 1994: 134).

Según Pichois y Rousseau el tema es lo que los pintores llaman asunto; por lo que hay reservar como hace el mismo R. Trousson en su ensayo metodológico Un probléme de littérature comparée: Les études de thémes, de 1965, el término de «motivo» para un concepto que abarque más y que designe bien una cierta actitud (por ejemplo, la sublevación), bien una situación impersonal, cuyos autores aún no hayan sido individualizados (por ejemplo, la oposición entre hermanos).

Concluyen afirmando que el tema se convierte en individualización de un motivo al pasar de lo general a lo particular. Así que la manera más clara de reagrupar los textos será según los temas (Tematología o Stoffgeschichte) (Pichois y Rousseau, 1969: 165-166). 
François Jost en su Introduction to comparative literature (1974) concibe el motivo como único elemento funcional de la Tematología. De hecho, los objetos que forman parte de su especulación teórica son los que denomina Motiv I (situaciones generales) y Motiv II (imágenes y topoi). En particular es el Motiv I el que se acerca a la definición de tema porque tiene la función de englobar: «Next to de motif in which we recognize the organizing principle of the whole there might be secondary motifs, of submotifs, since a work it is not necessarily built according to a merely linear architecture» (Jost, 1974: 183).

Shklovsky, a su vez, entiende el motivo más bien como la unidad narrativa más simple, correspondiente, imaginísticamente a las diversas necesidades de una mente primitiva y a las necesidades de la percepción ordinaria: «By motif I mean the simplest narrative unit, corresponding imagistically to the diverse needs of a primitive mind and to the needs of ordinary perception» (Shklovsky, 2009: 16).

Un aspecto importante que conviene detallar, igualmente, referente al motivo, es su repetición en la obra literaria de un autor; esta iteración se define con un término alemán que procede de la música, el leitmotiv, de concepción wagneriana. Cuando el motivo se reitera a lo largo de una obra y asume en ella un papel preciso, se hablará, por analogía con la música, de leitmotiv.

Para finalizar, sobre este aspecto hemos observado cómo el motivo, por su naturaleza dinámica, desde su origen ha sido percibido en su función como algo que implica movimiento, lo que activa la fábula o el relato. Un impulso que estimula los elementos para que concurran a la creación narrativa. A veces el motivo trasciende la relación jerárquica con el tema y deja de ser subsidiario. En algunos casos, y por algunos críticos, esta propensión dialéctica del motivo constituye la esencia misma de la obra literaria, un factor que le permite al escritor conseguir que la su creación llegue a poder ser reconocida por el lector.

\section{El RETORNo de la Tematología}

Hubo un tiempo en el que, como ya hemos mencionado, el estudio de los contactos entre literaturas europeas, generalmente reconocidas académicamente como de «primera categoría» había sido el paradigma tradicional de la Literatura Comparada, esta tradicional propensión teórica se quedó caduca antes la más científica teoría literaria (Pujante, 2017: 17), la crítica tematológica cayó en los abismos del olvido, pareciendo que su función critico- 
comparada se había agotado; y, sin embargo, en los primeros años 90, los estudios temáticos como un Fénix renacen de sus propias cenizas. El renovado apogeo de la Literatura Comparada, el regreso de la crítica temática fueron las características más llamativas de los finales del siglo XX y comienzos del siglo XXI como respuesta al «vacío de contenido» de la postmodernidad. Poco a poco, empero, a medida que las ideologías posmodernas se fueron relegando, se volvió cada vez más urgente la necesidad de llegar a lo real y de explorar nuevos espacios culturales, después de épocas intensamente volcadas de forma especular a la metaliteratura o a una intensa práctica de la intertextualidad concebida solo como una parcial herramienta de la escritura.

El libro emblema de este renacimiento fue The Return of Thematic Criticism del crítico Sollors, de 1993. En la introducción, el manifiesto de la nueva vitalidad temática, argumenta cómo se han acabado los años del auge del formalismo modernista, en los cuales hablar de contenido de una obra de arte era un anatema. Glosa afirmando que la crítica ya es en gran parte temática y que: «A focus on the themes of literature informs feminist, new historicist, ethnic, and even second-generation deconstructionist approaches. However, such practice is not always recognized » (Sollors, 1993: xiv). No obstante, el espectro del positivismo en parte atormenta los estudios temáticos con su presencia: «The specter of theoretically impoverished positivism still haunts thematic analysis, making it the approach to literature that dare not speak its name» (Sollors, 1993: xiv).

Algunos años antes, Claude Bremond y Thomas G. Pavel habían publicado un artículo con un título más evocativo que nunca, «La fin d'un anathème», en el que de una cierta manera se percibían signos precursores de esta nueva Tematología:

[...] l'assimilation au verre d'objets d'une autre matière, ou de sensations, d'états d'âme, et de toute entité susceptible de connotations hyalines. La thématisation ainsi entendue n'est ni un inventaire de thèmes préexistants ni leur création ex nihilo, mais l'actualisation méthodique de virtualités non encore exploitées. Ce qui dans l'œuvre, à chaque reprise, prend forme comme à-propos de ne se trouvait pas déjà là, dans le texte, indépendamment de l'appel que l'attention thématisant lui adresse : variables comme les dunes exposées au vent du désert, les reliefs et contours des champs thématiques se modèlent et se remodèlent à chaque changement de cap de la liberté interprétative (Bremond y Pavel, 1998: 217).

Desde entonces, este renovado espíritu de la Tematología ha seguido manteniéndose en auge durante las décadas posteriores. Hace cincuenta años, aproximadamente, casi nadie habría estado dispuesto a creer en un retorno del interés en los temas; dado que las escuelas criticas posteriores al positivismo habían aducido muchos y 
sólidos argumentos teóricos con el objetivo de desacreditar definitivamente un enfoque crítico que definían endeudado de manera irreversible del positivismo más ingenuo y con finalidad catalogadora, convirtiéndolo en objeto de un contencioso mítico.

Ceserani nos compendia lo que ha sucedido con los estudios tematológicos, es decir, cómo se ha desarrollado la nueva actitud hacia esta tipología de estudios, en algunos casos, y cómo unas miradas poco inclinadas a las explicaciones de esta corriente han sufrido una conversión total:

Si è assistito a delle vere e proprie conversioni, come quella di Claude Brémond, autore a suo tempo di una estremamente formalistica e astratta Logique du récit (1973, trad. it. 1977), e poi divenuto promotore di studi tematici, sia a livello teorico, con saggi e la cura di volumi e numeri speciali di riviste, insieme con Thomas Pavel, Joshua Landy e Cesare Segre, e il lancio della formula «la fin d'un anathème» (1985, trad. it. 2003; 1988; 1989; 1995), sia con applicazioni pratiche, come l'analisi tematica delle Mille e una notte (1991, trad. it. 1997). Hanno riacquistato peso gli esempi degli studiosi del folclore, primi elaboratori della distinzione classificatoria fra temi e motivi, dei seguaci parigini di Gaston Bachelard, di alcune scuole critiche come quella di Ginevra (Poulet, Rousset, Richard), di alcuni studiosi che hanno fatto degli studi tematici il loro cavallo di battaglia: Helmuth Petriconi ad Amburgo (1971),2 Raymond Trousson a Bruxelles (1964; 1965; 1981), Eugene H. Falk a Chapel Hill (1972), Theodor Ziolkowski a Princeton (1977; 1983; 1997; 1998), Robert Harrison a Stanford (1992a, trad. it. 1992b; 2002, trad. it. 2004). $\mathrm{Si}$ è rafforzata la presenza, anche teorica, di critici che per una ragione o per l'altra, si possono ricondurre all'area della critica tematica, da quelli orientati alla storia della cultura e del gusto come Mario Praz (1930, nuova ediz. 1996), a quelli orientati alla stilistica storica e allo studio dei topoi come Ernst Robert Curtius (1947, trad. it. 1992) o alla semantica storica come Leo Spitzer (1963, trad. it. 1967; nuova ediz. 2006), a quelli di matrice psicanalitica, da Charles Mauron, inventore della «psicocritica» (1964, trad. it. 1966) a Francesco Orlando, autore di uno studio esemplare (Ceserani, 2006: 26).

\section{TEMATOLOGÍA Y MULTICULTURALIDAD}

No podemos prescindir de los aspectos experienciales fisiológicos, psíquicos, sociales y culturales cuando hablamos de lo literario, teniendo en cuenta que es un producto de la creación humana, las fuentes vistas como construcción histórica del entramado de las diversas literaturas, deben buscarse dentro de la literatura y en cada campo protagonizado por la creación humana (Pujante, 2017: 29-30). Una de las últimas propuestas de reorientación tematológica, es la que ve sujeta a la cuestión de los Estudios Culturales. 
Charles Bernheimer ${ }^{9}$ individualiza nuevas y probables líneas futuras de desarrollo: «The space of comparison today involves comparisons between artistic productions usually studied by different disciplines, between various cultural constructions of those disciplines» (Brenheimer, 1995: 41-42).

En realidad, tal como destaca Pujante, el recorrido hacia nuevos espacios y sensibilidad culturales había empezado con Pichois y Rousseau que apoyan un universalismo cultural, defienden las ideas filosóficas de vario tipo, lo cual se había reafirmado en los primeros años ochenta, con el notable auxilio de Brunel. De igual forma Chevrel propende por una extensión y dilatación del comparatismo; así:

A esta literatura de carácter discursivo global ya nos conducía, como hemos apreciado antes, el manual de Pichois y Rousseau; lo que se confirmó en la refundación de 1983, con la colaboración de Pierre Brunel. Chervrel igualmente se manifiesta por la ampliación de comparatismo hacia otros discursos, considerando la problemática que entraña la inclusión de nuevas tecnologías, de medios de comunicación; lo que para defensores del viejo canon literario resulta improcedente (Pujante, 2017: 31).

Para Bernheimer (1995) lo que se pretende de la práctica profesional del campo de la Literatura Comparada, se puede identificar actualmente con una línea de pensamiento donde el espacio de la comparación comprende productos artísticos estudiados por diferentes diciplinas, o sea, entre construcciones culturales de estas distintas disciplinas; o, también, entre las tradiciones occidentales y no occidentales; entre el contacto pre y poscolonial de los pueblos colonizados; entre las construcciones de género definidas como masculina o femenina; entre la orientación heterosexual y homosexual; entre lo racial y étnico; entre una articulación hermenéutica del significado y el análisis concreto de las maneras formales y otros muchos aspectos. En resumida cuenta: «These ways of contestextualizing literature in the expanded fields of discourse, culture, ideology, race, and gender are so different from the old models of literary study according to authors, nations, periods, and genres that the term "literature" may no longer adequately describe our object of study» (Bernheimer, 1995: 42).

Constata, así, de manera perentoria, que estas nuevas formas de contextualizar la literatura en los campos más amplios del discurso, la cultura, la ideología, la raza y el género, determina casi una ruptura con los antiguos modelos de estudio literario, que reúnen su campo de investigación de acuerdo con los autores, las naciones, los períodos y los géneros;

\footnotetext{
${ }^{9}$ Fue director de un grupo de investigadores encargados por la ACLA (American Comparative Literature Association) de analizar el estado de los estudios comparatistas a finales del siglo veinte.
} 
y que el término «literatura» ya no puede describir adecuadamente el objeto de estudio de la Literatura Comparada, matizando que: «Another sign is the discussion that has occurred on same campuses about the possibility of adding phrase such as "and Cultural Studies", "and Cultural Critique", or and "Cultural Theory" to the departmental or program title in order to suggest ways in which the old destination may be inadequate» (Bernheimer, 1995: 42).

Por otra parte, la literatura se pone como centro de una confluencia que la transciende en las dicotomías del poder que se opone al no poder, al centro en contraste con la periferia, a la literatura canonizada opuesta a la emergente (Pujante, 2017: 16), de tal forma: «Que el hombre se agranda en lo común humano y se empequeñece en lo localista diferenciador (que por otra parte crea los conflictos y los odios), ese es el sentido común que alienta todo inicio de comparación» (Pujante, 2006: 89) y en paralelo, podemos afirmar que, nítidamente, el estudio de personajes y estereotipos femeninos y su representación en los textos literarios, pertenece a una consolidada tradición feminista, muy desarrollada en su aspecto comparativo. La tematización de la identidad femenina generalmente se refiere a la violencia física y/o psíquica que sufre la mujer en sus diferentes espacios vitales; los roles sociales de la mujer y sus relaciones con otros sujetos: las relaciones entre mujeres y las relaciones conflictivas con sujetos masculinos dentro del marco de las instituciones patriarcales (Naupert, 1998: 174).

En ese propósito, conviene matizar cómo a finales del siglo pasado se dio el redescubrimiento de la temática y de la tematología que, en general, ha adquirido desde entonces un nuevo impulso vital. En particular, en esta revitalización tuvo parte la escuela francesa; entre cuyos miembros hay que destacar a Claude Bremond que se ocupó de ese argumento en las revistas francesas Poetique y Communications.

¿Cuáles son las razones por las que no se identifica como simplemente temático el comparatismo multicultural?:

Las razones para este mutismo son evidentes: conceptos como tema, carácter, tipo o personaje se han revelado como demasiado neutros o inocuos para una crítica eminentemente politizada, que, además, ha asumido compromisos radicales en la batalla (multi)cultural dentro y fuera del entorno académico. Naturalmente sigue la crítica feminista estudiando temas rentables para sus respectivos intereses políticos y socioculturales, pero ya no los considera en los «simples» términos del análisis tematológico (Naupert, 1998: 174).

En el análisis más conciso de este vario y caleidoscópico panorama multicultural, también debemos tener en cuenta los importantes estudios que se refieren a la época colonial y postcolonial, y que se identifican con los African-American Studies, una de las corrientes más 
desarrolladas de la crítica moderna, basada en la búsqueda de una identidad racial por pertenencia a una raíz étnico-cultural común. El esclavismo, el color de la piel, la negritud como hecho discriminante y a la vez inclusivo, todo estos figuran como elementos demarcativos de una identidad compartida. Es importante matizar que, en términos sociodemográficos y macroeconómicos, en la cultura afroamericana se producen grados y configuraciones históricamente variados, incluidas las dificultades socioeconómicas, desigualdades y opresión (Hall, 1996: 717). El poscolonialismo empuja hacia una perspectiva temática de ruptura entre una visión precolonial y una visión identitaria postcolonial, una dicotomía entre identidad colonial y postcolonial. Esta identidad se exterioriza a través de la lengua, que adquiere una importancia primaria y tiene que hallar su propia dimensión identitaria dentro de un marco ajeno a lo considerado como la lengua del «patrón», ya que se han perdido las raíces lingüísticas. Así que no dentro de este marco, «For example, within his perspective there is no accounting for the fact (and implications thereof) that the so-called underclass has organized its own cultural voice (presently manifest as "hip-hop") that has significantly influenced “mainstream culture” 》 (Hall, 1996: 717).

En estos estudios en particular hay que matizar que es importante no asumir una relación causa-efecto unidireccional entre el externo sistemático y el interno-temático. Podemos comprender como los American-African Studies han hecho pocos intentos de incorporar principios temáticos la sensibilidad interna, el espíritu a través del cual los afroamericanos buscan transformarse a sí mismos y sus comunidades; y los que se han hecho son débiles y manifiestamente defectuosos:

However, his relatively few attempts to incorporate thematic principles-the internal sensibility, the ethos through which African Americans seek to transform themselves and their communities-are weak and glaringly flawed. As a result, the overall impact of his work, aside from inviting confusion as to the concept of the significance of race as an abstract statistical category with the concrete reality of race as a sociocultural divider, is to paint an exceedingly negative and nearly hopeless portrait of African American communities, especially the so-called "Black underclass" (Hall, 1996: 717).

El tema básico, o principio temático, que subyace a la forma y función de la identidad y de la cultura afroamericana es la dualidad, esa interacción que hay entre lo exterior (sociodemográfico, macroeconómico) e interior. El término dualidad se refiere a la oposición fundamental de las sensibilidades culturales que fundan, y de hecho definen, a los afroamericanos como un pueblo. En términos más amplios, el concepto de dualidad se 
refiere a la oposición de sensibilidades concernientes a la propia cultura o la de realidad negra que está relacionada con una realidad blanca.

El gran sociólogo y panafricanista W.E.B. DuBois, en su ensayo The souls of Black folk, registra de manera aguda y lacónica esta dualidad o conciencia doble: «One ever feels his two-ness, —an American, a Negro; two souls, two thoughts, two unreconciled strivings; two warring ideals in one dark body, whose dogged strength alone keeps it from being torn asunder» (DuBois, 2007: 45).

Estas dos fuerzas deben ser vistas como enteramente interactivas, transformándose mutuamente. En otras palabras, mientras que las fuerzas externas que determinan la estructura social a menudo construyen límites y barreras a la autodefinición, la autodeterminación y la autorrealización; las fuerzas generadas internamente sobre la sensibilidad cultural frecuentemente permiten a los individuos y comunidades superar los límites y también las barreras.

Thus it is also important not to assume a one-directional cause and-effect relationship between the external-systematic and the internal-thematic. Rather, they should be seen as wholly interactive and mutually transforming. In other words, whereas external forces determining social structure often construct limits and barriers to self-definition, self-determination, and self-actualization, internally generated forces on cultural sensibility often enable individuals and communities to push limits and overcome barriers (Hall, 1996: 717).

Indudablemente, la comparación tiene como afán continuo la recuperación de los fragmentos del espíritu humano. Comprender las varias identidades: «no debe llevarnos al perjuicio de asimilarnos (desde nuestra perspectiva) lo de los otros desdeñando la disparidad» (Pujante, 2017: 20) y que, superando las injusticias, las prevaricaciones colonialistas lleguemos al punto que: «[...] un estudiante hindú que tuvo que afrontar históricamente, por razones coloniales bien conocidas, a dos Shakespeare, el genio literario y el representante de los valore coloniales pueda acabar integrando su llegada a la vida cultural india» (Pujante, 2017: 20).

\section{CONCLUSIONES}

Analizando los Estudios Culturales, aunque sea de manera somera, hemos observado cómo seguramente se mueven, aunque no reconociéndolo, en un campo que pertenece a la Tematología y, desde este punto de vista teórico, en al campo de la crítica temática. 
Todo ocurre en un caleidoscópico mar de términos en el que la Tematología actualmente está inmersa y con alguna incertidumbre metodológica que caracteriza todavía esta rama de la Literatura Comparada. Pero, se puede sin duda afirmar que la importancia de los estudios temáticos es relevante en la literatura en general. Analizando los temas y los motivos resulta evidente cómo la literatura y sobre todo la literatura comparada tiene que considerarse como objeto imprescindible de estudio. Los temas son la materia prima «elaborable» o «elaborada» de la obra de arte literaria, la que el escritor forja y modela o de donde le llega la inspiración. Desde el principio, cuando estos dos elementos aparecieron en el campo de estudios literarios, con su matriz exclusivamente folklórica, lo que concernía el estudio de los cuentos populares, baladas, mitos, fábulas, romances, leyendas, chistes, etc., estos estudios se limitaban a recoger y clasificar el material folklórico como narrativa tradicional, hasta que los formalistas rusos, ocupándose del cuento a principios de siglo XX, empezaron a utilizar estos elementos folklóricos y de literatura popular como fuente de investigación.

El estudio del carácter funcional que estos constituyentes ejercen así mismo en la poesía y en la lírica es claramente de carácter literario, ya que en la literatura siempre se pone en evidencia su perfil migratorio y de transtextualidad. Los temas y los motivos migran de un texto a otro y de una época a otra teniendo siempre una matriz común, que a la vez es diferente en cada texto y en las diversas épocas, pero se integran en el propio discurso crítico (Baena, 2016: 31). Siguen, pues, a las mudanzas épocas, así como a los cambios de las costumbres, y son capaces de dar forma y filtrar el pensamiento del autor (tema) y de mover y de moverse dentro de la trama de un relato (motivo). "Uno y otro factor no son sino la representatividad temática de la singularidad y el discurso, de la creación como voz expansiva y la palabra perpetuamente realizándose; formas que retoman una mitificación emergente [...]» (Baena, 2010: 139).

Finalmente, en síntesis, podemos afirmar que cuando hablamos de tema literario, aunque la literatura sea un conjunto cuyos confines son lábiles, marcados por el término de la literalidad, traemos un componente sustancial de la literatura. El estudio del tema y de los motivos, de su capacidad de migrar, de variar sin perder sus rasgos principales, su fuerza comunicativa, su carga emisora, su capacidad estructuradora de un texto y de ser contenido fundamental de la trama, es imprescindible para conocer las conexiones entre obras literarias de diferentes culturas y ámbitos. Todos esto, en definitiva, no es sino un gran enriquecimiento 
Ue Actio nova: ReVISTA DE TEORÍA DE LA LITERATURA Y LITERATURA COMPARADA, 4: 571-598 DOI: https://doi.org/10.15366/actionova2020.4.024

desde un punto de vista metodológico, estableciendo en ello enlaces con civilizaciones, culturas y puentes con ámbitos de conocimientos diferentes. 


\section{BIBLIOGRAFÍA}

Albadalejo Mayordomo, Tomás (1998): Teoría de los mundos posibles y macroestructura narrativa: análisis de las novelas cortas de Clarín, Alicante, Publicacions Universitat Alacant.

Baena, Enrique (2010): Umbrales del imaginario, Barcelona, Anthropos.

Baena, Enrique (2016): Estudios de Teoría y Literatura Comparada: de Goethe a Machado y de las vanguardias a la poética actual, Barcelona, Anthropos.

Beller, Manfred (1984): «Tematología» en Schmeling, Manfred (Ed.) (1984): Teoría y praxis de la literatura comparada, traducción al español de Ignacio Torres Corredor, Barcelona, Alfa: 101-133.

Bernheimer, Charles (Ed.) (1995): Comparative literature in the age of multiculturalism, Baltimore, Johns Hopkins University Press.

Bremond, Claude; Pavel, Thomas (1988): «La fin d'un anathème», Communications, 47.1: 209220.

Brunel, Pierre; Chevrel, Yves (Eds.) (1994). Compendio de literatura comparada, traducción al español de Isabel Vericat Núñez, Madrid, Siglo XXI.

Ceserani, Remo (2008): «Il punto sulla critica tematica», Allegoria, 58: 25-33.

Croce, Benedetto (1903): «La "letteratura comparata"», La Critica. Rivista di letteratura, storia e Filosofia, 1: 77-80.

Diccionario de la Real Academia de la Lengua, en https://dle.rae.es/motivo?m=form (último acceso 23/07/2020)

Doležel, Lubomír (1972): «From motifemes to motifs», Poetics, 1(4): 55-90.

Du Bois, William Edward Burghardt (2008): The souls of black folk, Oxford, Oxford University Press.

Frenzel, Elisabeth (1963): Stoff-, Motiv-und Symbolforschung, Stuttgart, Metzler.

Frenzel, Elisabeth (1963): Stoffe der Weltliteratur: ein Lexikon dichtungsgeschichtlicher Längsschnittee. Stuttgart, Kröner, 1998, $9^{\mathrm{a}}$ ed. rev y aum.

Frenzel, Elisabeth (1966): Stoff-und Motivgeschichte, Berlin, E. Schimidt.

Frenzel, Elisabeth (1980): Diccionario de motivos de la literatura universal, traducción al español de Manuel Abella Martín, Madrid, Gredos.

García Berrio, Antonio; Hernández Fernández, Teresa (2008): Crítica literaria, Madrid, Cátedra.

García Berrio, Antonio (1973): Significado actual del formalismo ruso, Barcelona, Planeta. 
Gil-Albarellos Pérez-Pedrero, Susana (2003): «Literatura comparada y tematología: aproximación teórica.», Exemplaria, 7: 239-259.

Greimas, Algirdas Julien; Joseph Courtes (1990): Semiótica. Diccionario razonado de la teoría del lenguaje, Madrid, Gredos.

Grimm, Jacob \& Wilhelm (2015): Fiabe, prefacio de G. Cocchiara, traducción al italiano de Clara Bovero, Torino, Einaudi.

Guillén, Claudio (1985): Entre lo uno y lo diverso: Introducción a la literatura comparada. Barcelona, Crítica.

Hall, Perry A. (1996): «Introducing African American Studies: Systematic and Thematic Principles», Journal of Black Studies,26 (6): 713-734.

Jost, Francois (1974): Introduction to comparative literature, New York, Pegasus Publications.

Kaiser, Gerhard (1980): Einführung in die vergleichende literaturwissenschaft: forschungsstand, kritik, aufgaben, Darmstadt, Wissenschaftliche Buchgesellschaft.

Kalinowska, Sophie-Irène (1972): El concepto de motivo en literatura, Valparaíso, Ediciones Universitarias de Valparaíso.

Lausberg, Heinrich (1963): Elemente der literarischen Rhetorik, München, Hueber.

Levin, Harry (1968): «Thematics and criticism» en Peter, Demetez (Ed.) (1968): The disciplines of criticism, New Heven, Yale Universidty Press.

Naupert, Cristina (1998): «Afinidades (s)electivas. La tematología comparatista en los tiempos del multiculturalismo», Dicenda. Cuadernos de Filología Hispánica, 16: 171-183.

Naupert, Cristina (2001): La tematología comparatista: entre teoría y práctica: la novela de adulterio en la segunda mitad del siglo XIX, Madrid, Arco Libros.

Naupert, Cristina (2003): Tematología y comparatismo literario, Madrid, Arco Libros.

Orea Rojas, Mari Carmen (2018): «El Motivo Literario como elemento fundamental para la literatura comparada», Actio Nova: Revista de Teoría de la Literatura y Literatura Comparada, 2: 164-185. DOI: https://doi.org/10.15366/actionova2018.2

Pichois, Claude; Rousseau, André (1969): La literatura comparada, traducción al español Germán Colón Doménech, Madrid, Gredos.

Pimentel, L. A. (1993): «Tematología y transtextualidad», Nueva revista de filología hispánica, 41(1), 215-229. DOI: https://doi.org/10.24201/nrfh.v41i1.931.

Pujante, David (2006): «Sobre un nuevo marco teórico-metodológico apropiado a la actual tematología comparatista en España», Hispanic Horizon, 25: 82-115. 
Pujante, David (2017): Eros y Tánatos en la cultura occidental. Un estudio de metodología comparatista, Madrid, Calambur.

Segre, Cesare (1985): Principios de análisis del texto literario, traducción al castellano de María Pardo de Santayana, Barcelona, Crítica.

Shklovsky, Viktor $\left(2009^{4}\right)$ : Theory of prose, traducción al inglés de Benjamin Sher, Normal, Dalkey Archive Press.

Sollors, Werner (Ed.) (1993): The return of thematic criticism, Harvard University Press.

Tomachevski, Boris (1982): Teoría de la literatura, traducción al español de Marcial Suárez, Madrid, Akal.

Trocchi, Anna (1999): «Temas y mitos literarios» en Introduccion a la literatura comparada», en A. Gnisci(ed.) (1999), traducción al español de Luigi Giuliani, Barcelona, Critica: 129169.

Trousson, Raymond (1965): Un problème de littérature comparée: Les études de thèmes; essai de méthodologie, Paris, Minard.

Wellek, René; Warren, Austin (1974): Teoría literaria, traducción al español de José María Gimeno, Madrid, Gredos. 


\section{an}

Ue ACTIO NOVA: REVISTA DE TEORÍA DE LA LITERATURA Y LITERATURA COMPARADA, 4: 571-598 DOI: https://doi.org/10.15366/actionova2020.4.024

\section{SOBRE EL AUTOR}

\section{Salvatore Cristian Troisi}

Salvatore Cristian Troisi nacido en Legnano (Milano) Italia. Licenciado en Lenguas y Literaturas Extranjeras (Español e Inglés) por la Universidad de Palermo, con una tesis de literatura comparada sobre las influencias de la literatura inglesa en el poeta sevillano Luis Cernuda. Master en Profesorado en la Educación Secundaria en la Universidad de Milán y doctorando de Lingüística, Literatura y Traducción en la Universidad de Málaga actualmente profesor de secundaria de Lengua, Literatura y Cultura Española.

\section{Contact information:}

Universidad de Málaga,

Campus de, Bulevar Louis Pasteur, 27, 29010 Málaga,

cristiantroisi@uma.es

Contacto personal

Calle Goya 2, 12 4, 29002, Málaga

677290026, christiantroisi@gmail.com 